\title{
A Multi-Agent Linguistic-Style Large Group Decision-Making Method Considering Public Expectations
}

\author{
Gui-ju Zhu ${ }^{1} \cdot$ Chen-guang Cai ${ }^{2} \cdot{\text { Bin } \text { Pan }^{2} \cdot \text { Pei Wang }}^{3}$
}

Received: 5 August 2021 / Accepted: 18 October 2021

(c) The Author(s) 2021

\begin{abstract}
Focusing on the characteristics of public participation and large group decision making of major livelihood projects, this paper proposes a multi-agent linguistic-style large group decision-making method with the consideration of public expectations. Firstly, based on the discrimination degree of evaluating information, the comprehensive weight of each attribute is calculated with the principle of maximum entropy. Secondly, the expert preference information for different alternatives is clustered and several aggregations are formed. Thirdly, the preference conflict level of experts' group for each alternative is calculated, and a conflict-oriented experts' aggregation weight optimization model is constructed to ensure the effectiveness of conflict resolution. Fourthly, the public group's satisfaction is determined with the expectation distribution of public's and the expert group's preference, so as to obtain the sorting result of the decision alternatives. Finally, the effectiveness and applicability of the proposed method are verified by method comparison.
\end{abstract}

Keywords Public participation $\cdot$ Large group decision making $\cdot$ Multi-agent $\cdot$ Sociological expectation $\cdot$ Major livelihood projects

\section{Abbreviation \\ TOPSIS Technique for order preference by similarity to ideal solution}

\section{Introduction}

Mega projects which significantly affect the lives of multiple individuals are often referred to as "major livelihood projects". In recent years, the number of mass incidents caused by major livelihood projects has risen significantly, exerting a significant impact on the implementation and operation of the projects, and seriously damaging the relationship between local governments and the public. Therefore, the decision validity of major livelihood projects has a direct impact on the social risks $[1,2]$. To ensure the effectiveness

Chen-guang Cai

ccg169@126.com

1 School of Management, Hunan University of Technology and Business, Changsha 410205, China

2 School of Accounting, Hunan University of Finance and Economics, Changsha 410205, China

3 Business School, Guangdong University of Foreign Studies, Guangzhou 510420, China of major livelihood project decision making, the existing researches mainly improve the decision-making methods from following two aspects.

First, large group decision making is introduced into the decision model. Usually, major livelihood projects involve a wide range of stakeholders, and the opinions of many experts in different fields need to be considered when making decisions. Therefore, the decision making of major livelihood projects has the characteristics of large group decisions. In general, we define decision-making activities with more than 20 experts as large group decisions [3-5]. Due to the differences in interest relationships, attitudes, and knowledge backgrounds among experts, "preferences conflict" inevitably occurs among experts when making decisions. To obtain reasonable decision results, it is necessary to deal with preferences conflicts and help the experts group to reach a consensus $[6,7]$. According to the current literature, the methods used to deal with preferences conflict can be divided into two categories: (1) optimize the weight information or the expert preference by establishing a linear or nonlinear optimization model, to achieve resolution of decision conflicts [8, 9]; (2) construct an expert preference adjustment mechanism, which corrects the information of the members with large conflicts, to reduce the degree of decision conflicts $[10,11]$. In the decision-making process of 
major livelihood projects, the more the experts are involved, the more complex will the decision environment become. As a result, opinions among experts are more dispersed, and conflicts are more obvious, which further increases the difficulty of dealing with decision conflicts [12, 13].

The second is to consider the public participation in the decision-making model. Because major livelihood projects are closely related to the interests of the local people, whether the public are satisfied or not becomes one of the most important criteria to judge the validity of decision results. Public satisfaction mainly reflects the acceptance degree of the decision results by the majority of the public. Therefore, in the decision-making process of the major livelihood projects, it is necessary to collect and attach importance to the opinions of the public and try to ensure that the majority of the public are satisfied with the final decision results [14-17]. At present, studies considering public participation in decision-making activity mainly focus on the design of public participation mechanisms [18, 19], risk management of public participation [20,21], and effectiveness evaluation of public participation [22, 23]. These research results provide necessary theoretical and methodological support for public participatory decision making. Due to the lack of professional knowledge in the public, it is difficult for public individuals to give professional guidance when making decisions. Many public individuals just express their demands and sociological expectations, which can be used as important references for decision making. By comparing the differences between the attribute values of each alternative and the public expectations, group satisfaction of the public for each alternative is obtained, and the alternatives can be sorted [24-26]. Each individual may have a different expectation on the evaluation of major livelihood projects, resulting in discrete characteristics of the distribution of public expectations. Discrete public expectation cannot be directly used as decision reference points until they are addressed. Research into the setting of decision reference points has mainly focused on the number and forms of reference points setting [27, 28], the gap measure between reference points and attribute values [29], and the dynamic evolution characteristics of reference points [30]. The existing reference point setting methods are mostly based on known single data or a small amount of known data. Due to the characteristics of public expectations, which include large volume and high dispersion, it is difficult to set reference points based on public expectations. The existing reference point setting methods seldom involve the satisfaction of public expectations, which means that public demands and opinions cannot be fully reflected and expressed. For the decision making of major livelihood projects, how to set reference points according to the characteristics of public expectations needs to be further studied. It can be seen from the above that there are two primary groups involved in the decision-making process of major livelihood projects, namely the public group and the expert group. Therefore, this type of decision problem has the characteristics of multi-agent participation. Considering the high complexity of decision making, the evaluation information provided by the public and experts is usually given in the form of fuzzy numbers. At present, the common forms of fuzzy numbers include interval numbers [31], triangular fuzzy numbers [32], intuitionistic fuzzy numbers [33], linguistic variables [34], and so on. For the decision problems studied in this article, the public and experts are more likely to express their opinions in subjective ways. Therefore, we need to choose an appropriate expression form which we can better describe the subjective opinions of the public and experts. As a common expression form of subjective opinion, linguistic variables, characterized by simple expressions and easy operation, are widely used in the subjective evaluation or decision-making activities $[35,36]$. At present, the research of linguistic variable decision making has produced some promising results, but research of large group decision making with multi-agent linguistics is relatively rare. Based on the above analysis, we take the decision-making activities of major livelihood projects as the research subject. Based on the characteristics of major livelihood projects, and the consideration of public sociological expectation, a new multi-agent large group decision-making method is proposed in this paper. The contribution of this paper has three main aspects:

1. Both the public and experts are brought into an analytical framework for major livelihood project decision making. Previous studies have usually focused on a single agent's influence of the expert or public on the large group decision making, while relatively few studies have considered two or more agents simultaneously. The study of multi-agent factors is more practical.

2. A conflict-oriented experts' aggregation weights optimization model is constructed. The optimization model in this paper has two characteristics: first, the expert group's preference conflicts can be reduced to an acceptable level. Second, the adjustment range of the experts' aggregation weights is minimized, while ensuring the effect of conflict resolution.

3. The public group's satisfaction of each alternative is measured based on the distribution of public expectations, and the alternatives are evaluated based on the public group's satisfaction. The decision method proposed in this paper focuses more on the public expectations and tries to avoid the outbreak of public mass disturbance events in advance.

This paper is organized as follows: Sect. 2 introduces some preliminary knowledge. In Sect. 3, the problem 
description and some principles are described. In Sect. 4, an illustrative example is given. In Sect. 5, the method proposed in this paper is compared with other methods, and the effectiveness and applicability of our approach are proven. The paper is concluded in Sect. 6 .

\section{Preliminaries}

Assume the linguistic variable set is $\mathbf{S}=\left\{s_{\alpha} \mid \alpha=-\tau\right.$, $-\tau+1, \ldots,-1,0,1, \ldots, \tau-1, \tau\}$, where $s_{\alpha}$ represents the linguistic variable, $\alpha$ is the linguistic level, and $-\tau$ and $\tau$ are the lower and upper limits of the linguistic variable set $(\tau>0)$.

Definition 1 Assume $\widetilde{s}=\left[s_{\alpha_{1}}, s_{\alpha_{2}}\right]$, where $s_{\alpha_{1}}$ and $s_{\alpha_{2}}$ are the lower limit and upper limit of linguistic variables in s. $s_{\alpha_{1}}, s_{\alpha_{2}} \in \mathbf{S}, \mathbf{S}=\left\{s_{\alpha} \mid \alpha=-\tau,-\tau+1, \ldots,-1,0,1, \ldots, \tau-1, \tau\right\}$, $-\tau \leq \alpha_{1} \leq \alpha_{2} \leq \tau$. Then, $\widetilde{s}$ is called the uncertain linguistic variable [37].

Definition 2 Assume $\widetilde{s}_{1}=\left[s_{\alpha_{1}}, s_{\alpha_{2}}\right]$ and $\widetilde{s}_{2}=\left[s_{\beta_{1}}, s_{\beta_{2}}\right]$ are two uncertain linguistic variables. The rule of operation is as follows [37]:

(1) $\widetilde{s}_{1} \oplus \widetilde{s}_{2}=\left[s_{\alpha_{1}}, s_{\alpha_{2}}\right] \oplus\left[s_{\beta_{1}}, s_{\beta_{2}}\right]=\left[s_{\alpha_{1}+\beta_{1}}, s_{\alpha_{2}+\beta_{2}}\right]$,

(2) $\lambda \widetilde{s}_{1}=\lambda\left[s_{\alpha_{1}}, s_{\alpha_{2}}\right]=\left[s_{\lambda \alpha_{1}}, s_{\lambda \alpha_{2}}\right]$,

$$
\lambda_{1} \stackrel{\frac{1}{s}}{1} \oplus \lambda_{2} \stackrel{s}{s_{2}}=\left[s_{\lambda_{1} \alpha_{1}+\lambda_{2} \beta_{1}}, s_{\lambda_{1} \alpha_{2}+\lambda_{2} \beta_{2}}\right]
$$

Definition 3 Let $\widetilde{s}_{1}=\left[s_{\alpha_{1}}, s_{\alpha_{2}}\right]$ and $\widetilde{s}_{2}=\left[s_{\beta_{1}}, s_{\beta_{2}}\right]$ be two uncertain linguistic variables, and the evaluation scale of linguistic variables is $\tau$, then the distance between $\widetilde{s}_{1}$ and $\widetilde{s}_{2}$ is:

$d\left(\widetilde{s}_{1}, \widetilde{s}_{2}\right)=\frac{\left|\alpha_{1}-\beta_{1}\right|+\left|\alpha_{2}-\beta_{2}\right|}{4 \tau}$.

Theorem $1 d\left(\widetilde{s}_{1}, \widetilde{s}_{2}\right)$ has the following three properties: (1) boundedness, i.e., $0 \leq d\left(\widetilde{s}_{1}, \widetilde{s}_{2}\right) \leq 1$; (2) symmetry, i.e., $d\left(\widetilde{s}_{1}, \widetilde{s}_{2}\right)=d\left(\widetilde{s}_{2}, \widetilde{s}_{1}\right) ;(3)$ reflexivity, i.e., if $\widetilde{s}_{1}=\widetilde{s}_{2}, d\left(\widetilde{s}_{1}, \widetilde{s}_{2}\right)=0$

\section{Principles and Methods}

\subsection{Problem Description}

For a decision-making problem of major livelihood project, le t $Z=\left\{z_{1}, z_{2}, \ldots, z_{P}\right\}, \quad G=\left\{g_{1}, g_{2}, \ldots, g_{N}\right\}$, $\boldsymbol{\omega}=\left(\omega_{1}, \omega_{2}, \ldots, \omega_{N}\right)^{\mathbf{T}}$ and $E=\left\{e_{1}, e_{2}, \ldots, e_{M}\right\}$ be the alternative set, the attribute set, the attribute weights vector, and the decision experts set, respectively. Experts and publics give their evaluation values in the form of uncertain linguistic variables. Suppose the linguistic scale set is $\mathbf{S}=\left\{s_{\alpha} \mid \alpha=-\tau,-\tau+1, \ldots,-1,0,1, \ldots, \tau-1, \tau\right\}, \tau>0, \alpha$ is the linguistic level, $\mathbf{S}$ has $2 \tau+1$ scale variables, which are arranged in ascending order of linguistic level. Expert individuals give their attribute preferences for different alternatives by uncertain linguistic variables. Suppose the preference value of attribute $j$ given by expert $i$ for alternative $l$ is $\widetilde{v}_{i j}^{l}=\left[v_{i j}^{l L}, v_{i j}^{l U}\right]=\left[s_{t\left(v_{i j}^{l L}\right)}^{l L}, s_{t\left(v_{i j}^{l U}\right)}^{l U}\right] . i=1,2, \ldots, M ; j=1,2, \ldots, N$; $l=1,2, \ldots, P . v_{i j}^{l L}$ and $v_{i j}^{l U}$ are the lower and upper limits of $\widetilde{v}_{i j}^{l}$, respectively. The linguistic levels of $v_{i j}^{l L}$ and $v_{i j}^{l U}$ are $t\left(v_{i j}^{l L}\right)$ and $t\left(v_{i j}^{l U}\right)$, respectively. $t\left(v_{i j}^{I L}\right)=-\tau,-\tau+1, \ldots,-1,0,1, \ldots, \tau-1, \tau$, $t\left(v_{i j}^{l U}\right)=-\tau,-\tau+1, \ldots,-1,0,1, \ldots, \tau-1, \tau, \quad$ a n d $-\tau \leq t\left(v_{i j}^{l L}\right) \leq t\left(v_{i j}^{l U}\right) \leq \tau . V_{i}^{l}=\left(\widetilde{v}_{i 1}^{l}, \widetilde{v}_{i 2}^{l}, \ldots, \widetilde{v}_{i N}^{l}\right)$, as the preference vector of the decision expert $i$ for the alternative $l$, is formed by the preference values given by decision expert $i$ for $N$ attributes in the alternative $l$. The number of public participants is defined as $H$, and the uncertain linguistic expectation given by the public individual $h$ over attribute $j$ is $\widetilde{r}_{j}^{h}=\left[r_{j}^{h L}, r_{j}^{h U}\right]=\left[s_{t\left(r_{j}^{h L}\right)}, s_{t\left(r_{j}^{h U}\right)}\right], h=1,2, \ldots, H, j=1,2, \ldots, N$. $r_{j}^{h L}$ and $r_{j}^{h U}$ are the lower and upper limits of $\widetilde{r}_{j}^{h}$, respectively. The linguistic levels of $r_{j}^{h L}$ and $r_{j}^{h U}$ are $t\left(r_{j}^{h L}\right)$ and $t\left(r_{j}^{h U}\right)$ respectively, $t\left(r_{j}^{h L}\right)=-\tau,-\tau+1, \ldots,-1,0,1, \ldots, \tau-1, \tau$ $, t\left(r_{j}^{h U}\right)=-\tau,-\tau+1, \ldots,-1,0,1, \ldots, \tau-1, \tau, \quad$ a n d $-\tau \leq t\left(r_{j}^{h L}\right) \leq t\left(r_{j}^{h U}\right) \leq \tau$. The expectation vector of the public individual, $R^{h}=\left(\widetilde{r}_{1}^{h}, \widetilde{r}_{2}^{h}, \ldots, \widetilde{r}_{N}^{h}\right)$ is formed by the expectation values given by public individual $h$ for $N$ attributes.

\subsection{Attribute Weight Calculation}

(1) Attribute weights calculation based on expert preferences.

The preference vectors $V_{i}^{l}$ of $M$ experts on alternative $l$ form a vector set $\boldsymbol{\Omega}_{l}$. Calculate the average value of expert preference for attribute $j$ in $\boldsymbol{\Omega}_{l}$ by Eq. (2):

$\overline{\widetilde{v}}_{j}^{l}=\frac{1}{M}\left(\widetilde{v}_{1 j}^{l} \oplus \widetilde{v}_{2 j}^{l} \oplus \ldots \oplus \widetilde{v}_{M j}^{l}\right), \quad i=1,2, \ldots, M, i \in \boldsymbol{\Omega}_{l}$.

Calculate the average deviation degree of expert individual preference with respect to attribute $j$ in $\boldsymbol{\Omega}_{l}$ by Eq. (3):

$\psi_{j}^{l}=\frac{1}{M} \sum_{i=1 ; i \in \mathbf{\Omega}_{l}}^{M} d\left(\widetilde{v}_{i j}^{l}, \overline{\widetilde{v}}_{j}^{l}\right)$,

where the specific form of $d\left(\widetilde{v}_{i j}^{l}, \overline{\vec{v}}_{j}^{l}\right)$ is shown in Eq. (1), $\psi_{j}^{l} \in[0,1]$. As the value of $\psi_{j}^{l}$ increases, the differences of expert individual preferences over attribute $j$ increases. 
Let $\boldsymbol{\omega}_{1}=\left(\omega_{1}^{1}, \omega_{2}^{1}, \ldots, \omega_{N}^{1}\right)^{\mathbf{T}}$ be the attribute weights based on expert preferences, and calculate it using Eq. (4). The formula for calculation of $\omega_{j}^{1}$ is as follows:

$\omega_{j}^{1}=\frac{\sum_{l=1}^{P} \psi_{j}^{l}}{\sum_{j=1}^{N} \sum_{l=1}^{P} \psi_{j}^{l}}$.

(2) Attribute weights calculation based on public expectations.

The expectation vectors $R^{h}$ of $H$ public individuals form a vector set $\boldsymbol{\eta}$. Calculate the average value of public expectation for attribute $j$ in $\boldsymbol{\eta}$ using Eq. (5):

$\overline{\widetilde{r}}_{j}=\frac{1}{H}\left(\widetilde{r}_{j}^{1} \oplus \widetilde{r}_{j}^{2} \oplus \ldots \oplus \widetilde{r}_{j}^{H}\right), h=1,2, \ldots, H, h \in \mathbf{\eta}$.

Calculate the average deviation degree of public individual expectation to attribute $j$ in $\boldsymbol{\eta}$ using Eq. (6):

$\sigma_{j}=\frac{1}{H} \sum_{h=1 ; h \in \boldsymbol{\eta}}^{H} d\left(\widetilde{r}_{j}^{h}, \overline{\widetilde{r}}_{j}\right)$

The specific form of $d\left(\widetilde{r}_{j}^{h}, \overline{\widetilde{r}}_{j}\right)$ is shown in Eq. (1), $\sigma_{j} \in[0,1]$. As the value of $\sigma_{j}$ increases, the differences in the public individual expectations over attribute $j$ increases.

Let $\boldsymbol{\omega}_{2}=\left(\omega_{1}^{2}, \omega_{2}^{2}, \ldots, \omega_{N}^{2}\right)^{\mathbf{T}}$ be the attribute weight based on public expectations, and calculate it by Eq. (7). The formula of $\omega_{j}^{2}$ is as follows:

$\omega_{j}^{2}=\frac{\sigma_{j}}{\sum_{j=1}^{N} \sigma_{j}}$.

(3) Determination of multi-agent comprehensive attribute weights.

Let $\boldsymbol{\omega}=\left(\omega_{1}, \omega_{2}, \ldots, \omega_{N}\right)^{\mathbf{T}}$ be the multi-agent comprehensive attribute weights. The weight range of attribute $j$ is $\omega_{j}=\left[\omega_{j}^{L}, \omega_{j}^{U}\right]$, where $\omega_{j}^{L}=\min \left(\omega_{j}^{1}, \omega_{j}^{2}\right), \omega_{j}^{U}=\max \left(\omega_{j}^{1}, \omega_{j}^{2}\right)$. Then, utilize the optimization model (M-1), which is established based on the maximum entropy principle, to determine the comprehensive attribute weights.

$\max \varphi\left(\omega_{j}\right)=-\sum_{j=1}^{N} \omega_{j} \ln \omega_{j}$

$\left\{\begin{array}{l}\omega_{j}^{L} \leq \omega_{j} \leq \omega_{j}^{U} \\ \sum_{j=1}^{N} \omega_{j}=1\end{array}\right.$.

Theorem 2 The optimal solution of Model (M-1) must exist.
Proof The constraint of $\omega_{j}$ is a bounded closed set. When the attribute weights are allowed to be adjusted sufficiently, there must exist a suitable $\omega_{j}$ that can satisfy $\sum_{j=1}^{N} \omega_{j}=1$ with the constraint of $\omega_{j}^{L} \leq \omega_{j} \leq \omega_{j}^{U}$. Therefore, the feasible region of the attribute weights is a nonempty set. Theorem 2 is proved.

\subsection{Determination of the Expert Group's Preference}

(1) Clustering of expert individuals' preferences.

Set Eq. (8) as the clustering formula for calculating the similarity between expert individuals' preferences, $\operatorname{Sim}\left(V_{i_{1}}^{l}, V_{i_{2}}^{l}\right) \in[0,1]$. As the value of $\operatorname{Sim}\left(V_{i_{1}}^{l}, V_{i_{2}}^{l}\right)$ increases, the similarity between $V_{i_{1}}^{l}$ and $V_{i_{2}}^{l}$ increases. Set a reasonable clustering threshold $\lambda_{l}\left(\lambda_{l} \in[0,1]\right)$, and the expert individuals' preferences in $\boldsymbol{\Omega}_{l}$ are divided into several aggregations by using a previously published method [38].

$\operatorname{Sim}\left(V_{i_{1}}^{l}, V_{i_{2}}^{l}\right)=1-\sum_{j=1 ; i_{1}, i_{2} \in \mathbf{\Omega}_{l}}^{N} \omega_{j} d\left(\widetilde{v}_{i_{1}}^{l} j \widetilde{v}_{i_{2} j}^{l}\right)$.

The specific form of $d\left(\widetilde{v}_{i_{1} j}^{l}, \widetilde{v}_{i_{2} j}^{l}\right)$ is shown in Eq. (1).

Theorem $3 \operatorname{Sim}\left(V_{i_{1}}^{l}, V_{i_{2}}^{l}\right)$ has the following three properties: (1) boundedness, i.e., $0 \leq \operatorname{Sim}\left(V_{i_{1}}^{l}, V_{i_{2}}^{l}\right) \leq 1$; (2) symmetry, i.e., $\operatorname{Sim}\left(V_{i_{1}}^{l}, V_{i_{2}}^{l}\right)=\operatorname{Sim}\left(V_{i_{2}}^{l}, V_{i_{1}}^{l}\right)$; (3) reflexivity, i.e., if $V_{i_{1}}^{l}=V_{i_{2}}^{l}, \operatorname{Sim}\left(V_{i_{1}}^{l}, V_{i_{2}}^{l}\right)=1$.

After the clustering operation, the expert individuals' preferences in $\boldsymbol{\Omega}_{l}$ are divided into several aggregations, with approximately consistent preferences. Assume the number of aggregations formed in $\boldsymbol{\Omega}_{l}$ is $K_{l}\left(1 \leq K_{l} \leq M\right)$, and the number of experts in the $k_{\mathrm{th}}$ aggregation $C_{k}^{l}$ is $n_{k}^{l}$. Suppose each expert in $\boldsymbol{\Omega}_{l}$ has the same importance, calculate the expert aggregation preference of attribute $j$ over aggregation $C_{k}^{l}$ using Eq. (9), and then obtain the aggregation's preference vector $Y_{k}^{l}\left(Y_{k}^{l}=\left(\widetilde{y}_{k 1}^{l}, \widetilde{y}_{k 2}^{l}, \ldots, \tilde{y}_{k N}^{l}\right)\right)$.

$\widetilde{y}_{k j}^{l}=\frac{1}{n_{k}^{l}}\left(\widetilde{v}_{1 j}^{l} \oplus \widetilde{v}_{2 j}^{l} \oplus \ldots \oplus \widetilde{v}_{n_{k}^{l} j}^{l}\right), i=1,2, \ldots, n_{k}^{l}, i \in C_{k}^{l}$.

Give weights to each aggregation based on the number of experts in it. The expert aggregation weights in $\boldsymbol{\Omega}_{l}$ are shown in Eq. (10):

$\mathbf{w}_{l}=\left(w_{1}^{l}, w_{2}^{l}, \ldots, w_{K_{l}}^{l}\right)^{\mathbf{T}}=\left(\frac{n_{1}^{l}}{M}, \frac{n_{2}^{l}}{M}, \ldots, \frac{n_{K_{l}}^{l}}{M}\right)^{\mathbf{T}}$.

Calculate the expert group's preference of attribute $j$ in $\boldsymbol{\Omega}_{l}$ by Eq. (11), and then determine the expert group's preference vector $Y_{l}\left(Y_{l}=\left(\widetilde{y}_{1}^{l}, \tilde{y}_{2}^{l}, \ldots, \widetilde{y}_{N}^{l}\right)\right)$ : 
$\tilde{y}_{j}^{l}=w_{1}^{l} \tilde{y}_{1 j}^{l} \oplus w_{2}^{l} \tilde{y}_{2 j}^{l} \oplus \ldots \oplus w_{K_{l}}^{l} \tilde{y}_{K_{l} j}^{l}, \quad k=1,2, \ldots, K_{l}, k \in \mathbf{\Omega}_{l}$.

(2) Conflict measurement of the expert group's preference. According to the above we know, the expert preferences in $\boldsymbol{\Omega}_{l}$ are divided into several aggregations, and the expert preferences in the same aggregation are generally consistent, but the preference values between two aggregations are not always consistent. It is known that the expert group's preference is formed by several aggregation preferences in the same set. As a result, the expert group's preference is often inconsistent with the expert aggregation preference. To ensure the effectiveness of gathering the expert individuals' preference, it is necessary to measure and cope with the inconsistency of expert group's preference. The preference conflict of expert aggregation is defined as the inconsistency between the expert group's preference and the expert aggregation's preference. Then, the preference conflict of expert group can be obtained by the aggregation weights and the preference conflicts of expert aggregation. See Definitions 4 and 5 for specific explanations.

Definition 4 The preference conflict of expert aggregation $C_{k}^{l}$ is defined as:

$\operatorname{CCI}\left(Y_{k}^{l}\right)=\sum_{j=1 ; k \in C_{k}^{l}}^{N} \omega_{j} d\left(\widetilde{y}_{k j}^{l}, \tilde{y}_{j}^{l}\right)$.

The specific form of $d\left(\widetilde{y}_{k j}^{l}, \widetilde{y}_{j}^{l}\right)$ is shown in Eq. (1), $\mathrm{CCI}\left(Y_{k}^{l}\right) \in[0,1]$. As the value of $\mathrm{CCI}\left(Y_{k}^{l}\right)$ increases, the preference conflict of aggregation $C_{k}^{l}$ increases.

Definition 5 The preference conflict of expert group over $\mathbf{\Omega}_{l}$ is defined as:

$\operatorname{GCI}\left(Y_{l}\right)=\sum_{k=1, k \in \Omega_{l}}^{K_{l}} w_{k}^{l} \operatorname{CCI}\left(Y_{k}^{l}\right)$.

where $\operatorname{GCI}\left(Y_{l}\right) \in[0,1]$. As the value of $\operatorname{GCI}\left(Y_{l}\right)$ increases, the preference conflict of the expert group over $\boldsymbol{\Omega}_{l}$ increases.

(3) Construction of the expert aggregation weight optimization model-oriented conflicts.

Set the conflict threshold of the expert group's preference as $\theta(\theta \in[0,1])$. When $\operatorname{GCI}\left(Y_{l}\right) \leq \theta$, the preference conflict level of the expert group in $\boldsymbol{\Omega}_{l}$ is acceptable. Otherwise, when $\operatorname{GCI}\left(Y_{l}\right)>\theta$, the preference conflict level of the expert group in $\boldsymbol{\Omega}_{l}$ is too high and needs to be dealt with again. We build a weight optimization model to adjust the aggregation weights aiming at reducing the preference conflict of expert group.
There are two main goals of constructing the aggregation weights optimization model. The first one is to reduce the preference conflicts of the expert group to an acceptable level through the optimization of aggregation weights, i.e., $\operatorname{GCI}\left(Y_{l}\right) \leq \theta$. The second is to minimize the adjustment range of the expert aggregation weights in the precondition of ensuring conflict resolution. Then, utilize the optimization model (M-2), which is established based on the maximum entropy principle, to determine the updated expert aggregation weights. Based on this operation, the adjusted expert aggregation weights of $\boldsymbol{\Omega}_{l}$ is $\widetilde{\mathbf{w}}_{l}=\left(\widetilde{w}_{1}^{l}, \widetilde{w}_{2}^{l}, \ldots, \widetilde{w}_{K_{l}}^{l}\right)^{\mathbf{T}}$. The optimization model of expert aggregation weights is established as shown in (M-2).

$$
\begin{aligned}
& \min F\left(\widetilde{w}_{k}^{l}\right)=\sqrt{\sum_{k=1, k \in \Omega_{l}}^{K_{l}}\left(\widetilde{w}_{k}^{l}-w_{k}^{l}\right)^{2}} \\
& \text { s.t. }\left\{\begin{array}{c}
\mathrm{GCI}\left(Y_{l}\right) \leq \theta \\
\sum_{l} \widetilde{w}_{k}^{l}=1 \\
\sum_{k=1, k \in \Omega_{l}}^{l} \\
\left|\widetilde{w}_{k}^{l}-w_{k}^{l}\right| / w_{k}^{l} \leq G \Delta_{0}, \\
\Delta_{0}>0 \\
0 \leq \widetilde{w}_{k}^{l} \leq 1 \\
G=1,2, \ldots,\left\lceil(M-1) / \Delta_{0}\right\rceil
\end{array}\right.
\end{aligned}
$$

where $G$ is the optimization round of experts' aggregation weights, and $\Delta_{0}$ is the step size of the maximum adjustment proportion for experts' aggregation weights. When using the optimization model to adjust the experts' aggregation weights for the first time, set $G=1$ and the maximum adjustment proportion of $w_{k}^{l}$ is $\Delta_{0}$. Then, solve the model based on these constraints in (M-2). If the model has a feasible solution, the experts' aggregation weight optimization is completed, and new experts' aggregation weights are obtained. If the model has no solution, set $G=2$ and expand the maximum adjustment proportion to $2 \Delta_{0}$. By analogy, continue to solve the model until a feasible solution is obtained. For the initial value of $w_{j}^{l}$, there is at least one expert in the corresponding aggregation $C_{k}^{l}$. According to Eq. (10), the minimum possible value of the experts' aggregation weight $w_{j}^{l}$ is $1 / M$, and the maximum possible value of experts' aggregation weight $w_{j}^{l}$ is 1 . Therefore, it needs to take about $M-1$ times adjustments with Model (M-2) to adjust the value of the weight $w_{j}^{l}$ from $1 / M$ to 1 . Then, according to the constraint conditions $\left|\widetilde{w}_{k}^{l}-w_{k}^{l}\right| / w_{k}^{l} \leq G \Delta_{0}$, it can be deduced that the maximum value of the optimization round is $\left\lceil(M-1) / \Delta_{0}\right\rceil$.

Theorem 4 Model (M-2) must have feasible solutions. 
Proof The constraint condition of $\widetilde{w}_{k}^{l}$ is a bounded closed set. When the expert aggregation weights are allowed to be adjusted sufficiently, there exists a suitable $\widetilde{w}_{k}^{l}$ that can satisfy $\sum_{k=1}^{K_{l}} \widetilde{w}_{k}^{l}=1$ with the constraint of $0 \leq \widetilde{w}_{k}^{l} \leq 1$. Therefore, the feasible region of the expert aggregation weights is a nonempty set. In addition, when the expert aggregation weights of $\boldsymbol{\Omega}_{l}$ needs to be adjusted, and the preference conflict of the expert group in $\boldsymbol{\Omega}_{l}$ must satisfy $\operatorname{GCI}\left(Y_{l}\right)>\theta$. After the expert aggregation weights of $\boldsymbol{\Omega}_{l}$ are optimized once or several times, we assume the weight of a certain expert aggregation reaches 1 , and the other aggregation weights are 0 , then we can get $\operatorname{GCI}\left(Y_{l}\right)=0<\theta$. Because there is no breakpoint in $\widetilde{w}_{k}^{l}$ within the range of $[0,1], \operatorname{GCI}\left(Y_{l}\right)$ is a continuous bounded function with the constraint of $\widetilde{w}_{k}^{l}$, and there must be a feasible solution satisfying $\operatorname{GCI}\left(Y_{l}\right) \leq \theta$. Therefore, Theorem 4 is proved.

\subsection{Distribution Determination of Public Group's Expectation}

Because the public's expectations to an attribute have the characteristics of large scale and high dispersion, it is necessary for them to be further counted and classified so as to become the valid reference for decision-making activities. In view of this, we collect the expectations given by all public participants to different attributes, and then conduct statistics and classification based on the linguistic scale to obtain the statistical distribution of public group's expectation.

The number of public participants is $H$, so the expectation value of each public individual in the statistical result of public group's expectation accounts for $1 / H$. Suppose the expectation value of the uncertain linguistic variable given by the

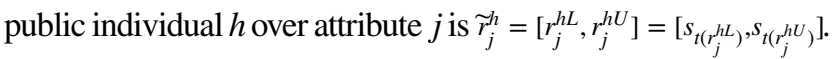
$\widetilde{r}_{j}^{h}$ includes $t\left(r_{j}^{h U}\right)-t\left(r_{j}^{h L}\right)+1$ scaling variables, which form the set $\mathbf{S}\left(\widetilde{r}_{j}^{h}\right)=\left\{s_{t\left(r_{j}^{h L}\right)}, s_{t\left(r_{j}^{h L}\right)+1}, \ldots, s_{t\left(r_{j}^{h U}\right)}\right\}$. Assume the value of $\widetilde{r}_{j}^{h}$ follows an equal probability distribution in the linguistic scale of $\mathbf{S}\left(\widetilde{r}_{j}^{h}\right)$, that is, the probability that the value of $\widetilde{r}_{j}^{h}$ falls in any scale of $\mathbf{S}\left(\widetilde{r}_{j}^{h}\right)$ is $1 /\left(t\left(r_{j}^{h U}\right)-t\left(r_{j}^{h L}\right)+1\right)$. According to the probability distribution of the public individual's expectation at different scales, allocate the statistical proportion of each public expectation using Eq. (14).

$q_{\widetilde{r}_{j}^{h}}\left(s_{\alpha}\right)=\left\{\begin{array}{ll}\frac{1}{\left(t\left(r_{j}^{h U}\right)-t\left(r_{j}^{h L}\right)+1\right) H}, & s_{\alpha} \in \mathbf{S}\left(\widetilde{r}_{j}^{h}\right), s_{\alpha} \in \mathbf{S} \\ 0, & s_{\alpha} \notin \mathbf{S}\left(\widetilde{r}_{j}^{h}\right), s_{\alpha} \in \mathbf{S}\end{array}\right.$,

where $q_{\widetilde{r}_{j}^{h}}\left(s_{-\tau}\right)+q_{\widetilde{r}_{j}^{h}}\left(s_{-\tau+1}\right)+\ldots+q_{\widetilde{r}_{j}^{h}}\left(s_{\tau-1}\right)+q_{\widetilde{r}_{j}^{h}}\left(s_{\tau}\right)=1 / H$.

The statistical proportion of the public group's expectations at linguistic scale $s_{\alpha}$ over attribute $j$ is obtained by Eq. (15): $q_{j}\left(s_{\alpha}\right)=\sum_{h=1 ; h \in \eta}^{H} q_{\widetilde{r}_{j}^{h}}\left(s_{\alpha}\right)$,

where $q_{j}\left(s_{-\tau}\right)+q_{j}\left(s_{-\tau+1}\right)+\ldots+q_{j}\left(s_{\tau-1}\right)+q_{j}\left(s_{\tau}\right)=1$.

\subsection{Calculation of the Public Group's Satisfaction}

The expert group's preference mainly reflects the preference degree of the expert group to different attributes in each alternative, while the public group's expectation mainly refers to the public group's expectation or appeals to different attributes without involving specific alternatives. For each alternative, we calculate the probability of which the expert group's preference is not less than the public group's expectation to different attributes. Combined with the distribution of the public group's expectation, the public group's satisfaction of each alternative can be obtained.

Suppose a certain linguistic scale of the public groups expectation for attribute $j$ is $s_{\alpha}$. Then, we define $b_{j}^{l}\left(s_{\alpha}\right)$ as the public group's satisfaction of attribute $j$ in alternative $l$ at the linguistic scale $s_{\alpha}$. Specifically, $b_{j}^{l}\left(s_{\alpha}\right)$ is the probability that the expert group's preference of attribute $j$ in alternative $l$ is not less than the corresponding public group's expectation under the linguistic scale $s_{\alpha}$.

It is known that the expert group's preference of attribute $j$ over alternative $l$ is $\widetilde{y}_{j}^{l}=\left[y_{j}^{l L}, y_{j}^{l U}\right]=\left[s_{t\left(y_{j}^{l L}\right)}, s_{t\left(y_{j}^{l U}\right)}\right]$, $-\tau \leq t\left(y_{j}^{l L}\right) \leq t\left(y_{j}^{l U}\right) \leq \tau$. The calculation of $b_{j}^{l}\left(s_{\alpha}\right)$ is shown in Table 1.

After calculating the public group's satisfactions of attribute $j$ in alternative $l$ at different linguistic scales, and combining the statistical distribution of public group's expectation over attribute $j$, the public group's comprehensive satisfaction of attribute $j$ in alternative $l$ is obtained, as shown in Eq. (16).

$$
\begin{aligned}
b_{j}^{l}= & q_{j}\left(s_{-\tau}\right) b_{j}^{l}\left(s_{-\tau}\right)+q_{j}\left(s_{-\tau+1}\right) b_{j}^{l}\left(s_{-\tau+1}\right)+\ldots \\
& +q_{j}\left(s_{\tau-1}\right) b_{j}^{l}\left(s_{\tau-1}\right)+q_{j}\left(s_{\tau}\right) b_{j}^{l}\left(s_{\tau}\right) .
\end{aligned}
$$

Further, the public group's satisfaction of alternative $l$ can be calculated by attribute weights, as shown in Eq. (17).

Table 1 Formulas for calculating the public group's satisfaction at different linguistic scales

\begin{tabular}{lll}
\hline $\begin{array}{l}\text { Num- } \\
\text { bers }\end{array}$ & $\begin{array}{l}\text { Relationship between } \\
s_{\alpha} \text { and } \widetilde{y}_{j}^{l}\end{array}$ & Public group's satisfaction $b_{j}^{l}\left(s_{\alpha}\right)$ \\
\hline 1 & $s_{\alpha} \leq y_{j}^{l L}$ & 1 \\
2 & $y_{j}^{I L}<s_{\alpha} \leq y_{j}^{I U}$ & $\left(t\left(y_{j}^{l U}\right)-\alpha\right) /\left(t\left(y_{j}^{l U}\right)-t\left(y_{j}^{l L}\right)\right)$ \\
3 & $s_{\alpha}>y_{j}^{l U}$ & 0 \\
\hline
\end{tabular}


$b_{l}=\sum_{j=1}^{N} \omega_{j} b_{j}^{l}$

The specific steps of the proposed method are as follows: Step 1 Determine the attribute weights $\boldsymbol{\omega}=\left(\omega_{1}, \omega_{2}, \ldots, \omega_{n}\right)^{\mathbf{T}}$ by Eqs. (2-7) and Model (M-1).

Step 2 Take Eq. (8) as the clustering formula, and set the reasonable clustering threshold as $\lambda_{l}\left(\lambda_{l} \in[0,1]\right)$. Then, divide the expert preferences in $\boldsymbol{\Omega}_{l}$ into several aggregations by clustering operation. The expert aggregation's preference $Y_{k}^{l}$ and the expert group's preference $Y_{l}$ of $\boldsymbol{\Omega}_{l}$ are obtained with Eqs. (9-11).

Step 3 Calculate the expert group's preference conflicts of $\boldsymbol{\Omega}_{l}\left(\operatorname{GCI}\left(Y_{l}\right)\right)$ using Eqs. $(12,13)$. Compare the expert group's preference conflict $\operatorname{GCI}\left(Y_{l}\right)$ and the conflict threshold $\theta$, if $\mathrm{GCI}\left(Y_{l}\right) \leq \theta$, Step 5 is entered, otherwise Step 4 is entered.

Step 4 Use Model (M-2) to optimize the expert aggregation weights of $\boldsymbol{\Omega}_{l}$ with oversize conflicts, and obtain the optimized aggregation weight $\widetilde{\mathbf{w}}_{l}\left(\widetilde{\mathbf{w}}_{l}=\left(\widetilde{w}_{1}^{l}, \widetilde{w}_{2}^{l}, \ldots, \widetilde{w}_{K_{l}}^{l}\right)^{\mathbf{T}}\right)$. Then, Step 5 is entered.

Step 5 Determine the proportional distribution of the public group's expectations under different linguistic scales using Eqs. $(14,15)$.

Step 6 Calculate the public group's satisfaction of different alternatives and determine the optimal alternative by using Eqs. $(16,17)$.

\section{Analysis of Numerical Example}

\subsection{Background Description}

A public rental housing project has entered the start-up siting stage, which is built in a city in central China. As a provincial demonstration project for people's livelihood in 2021, this project is expected to provide more than 3500 units of suites, which mainly focuses on solving the housing problem for college graduates, migrant workers and lowincome groups.

Project site selection is an important task. Through the analysis of the floor area, urban land planning, the surrounding facilities and other factors, the relevant departments put forward three site selection alternatives. To make the optimal decision, it is necessary to evaluate these alternatives with the opinions of the experts and publics. According to experts' discussions and public's opinions, transportation convenience, quality of supporting facilities and environmental safety are the three important factors affecting the site selection of the project. Therefore, this paper takes transportation convenience $\left(g_{1}\right)$, quality of supporting facilities $\left(g_{2}\right)$ and environmental safety $\left(g_{3}\right)$ as the decision attributes to evaluate the three site selection alternatives.

Assume that 20 experts from different departments such as the transportation department, environmental protection department, urban management department and land management department, participate in the decision-making activities. All the 20 experts give their preferences in the form of uncertain linguistic variables, and the scaling coefficient is 5 (i.e., $\tau=5$ ). The relationship between evaluation value and linguistic variable is shown in Table 2.

The 20 experts' preferences to different attributes for the three alternatives are shown in Table 3.

The direct stakeholders of public rental housing project are the relevant public groups, such as college graduates, migrant workers and low-income groups. The opinions of these public groups should be fully taken into account when selecting project sites. The government can introduce the project's basic information and the advantages and disadvantages of three alternatives through the Internet, broadcasting and leaflets to make the public better understand the project. Then, the government can obtain some public's expectations for the three attributes through online questionnaires or paper questionnaires. According to the number of returned questionnaires, there are 4713 effective public groups participating. Similar to the expression form of the expert opinions, the public expectations are given in the form of uncertain linguistic variables, and the linguistics scale coefficient is also 5 . The public's expectations for different attributes are shown in Table 4 (due to space limitations, part of the data is omitted).

\subsection{Decision Process and Results}

\section{(1) Calculation of the attribute weights}

The attribute weights based on expert preferences are determined by using Eqs. (2-4), and the result is $\boldsymbol{\omega}_{1}=(0.42,0.22,0.36)^{\mathbf{T}}$. Equations (5-7) are used to determine the three attribute weights based on public preferences, and the result is $\boldsymbol{\omega}_{2}=(0.27,0.30,0.43)^{\mathbf{T}}$. Use Model (M-1) to determine the multi-agent comprehensive weight of each attribute and the result is $\boldsymbol{\omega}=(0.34,0.30,0.36)^{\mathbf{T}}$.
Table 2 The relationship between evaluation value and linguistic variable

\begin{tabular}{lllllll}
\hline Evaluation value & Extremely poor & Terribly poor & Very poor & Poor & Slightly poor & Fair \\
\hline Linguistic variable & $s_{-5}$ & $s_{-4}$ & $s_{-3}$ & $s_{-2}$ & $s_{-1}$ & $s_{0}$ \\
Evaluation value & Slightly good & Good & Very good & Extremely good & Perfect & - \\
Linguistic variable & $s_{1}$ & $s_{2}$ & $s_{3}$ & $s_{4}$ & $s_{5}$ & - \\
\hline
\end{tabular}


Table 3 The expert preferences to different attributes for the three alternatives

\begin{tabular}{|c|c|c|c|c|c|c|c|c|}
\hline Alternatives & Experts & Attribute1 & Attribute 2 & Attribute 3 & Experts & Attribute 1 & Attribute 2 & Attribute 3 \\
\hline \multirow[t]{10}{*}{1} & $V_{1}^{1}$ & {$\left[s_{5}, s_{5}\right]$} & {$\left[s_{5}, s_{5}\right]$} & {$\left[s_{0}, s_{3}\right]$} & $V_{11}^{1}$ & {$\left[s_{5}, s_{5}\right]$} & {$\left[s_{3}, s_{5}\right]$} & {$\left[s_{0}, s_{3}\right]$} \\
\hline & $V_{2}^{1}$ & {$\left[s_{5}, s_{5}\right]$} & {$\left[s_{3}, s_{5}\right]$} & {$\left[s_{2}, s_{3}\right]$} & $V_{12}^{1}$ & {$\left[s_{5}, s_{5}\right]$} & {$\left[s_{3}, s_{5}\right]$} & {$\left[s_{0}, s_{3}\right]$} \\
\hline & $V_{3}^{1}$ & {$\left[s_{1}, s_{1}\right]$} & {$\left[s_{4}, s_{5}\right]$} & {$\left[s_{2}, s_{3}\right]$} & $V_{13}^{1}$ & {$\left[s_{1}, s_{1}\right]$} & {$\left[s_{4}, s_{5}\right]$} & {$\left[s_{2}, s_{3}\right]$} \\
\hline & $V_{4}^{1}$ & {$\left[s_{3}, s_{4}\right]$} & {$\left[s_{3}, s_{4}\right]$} & {$\left[s_{3}, s_{4}\right]$} & $V_{14}^{1}$ & {$\left[s_{3}, s_{4}\right]$} & {$\left[s_{3}, s_{4}\right]$} & {$\left[s_{3}, s_{4}\right]$} \\
\hline & $V_{5}^{1}$ & {$\left[s_{3}, s_{5}\right]$} & {$\left[s_{3}, s_{5}\right]$} & {$\left[s_{0}, s_{3}\right]$} & $V_{15}^{1}$ & {$\left[s_{1}, s_{1}\right]$} & {$\left[s_{4}, s_{5}\right]$} & {$\left[s_{2}, s_{3}\right]$} \\
\hline & $V_{6}^{1}$ & {$\left[s_{5}, s_{5}\right]$} & {$\left[s_{3}, s_{5}\right]$} & {$\left[s_{0}, s_{3}\right]$} & $V_{16}^{1}$ & {$\left[s_{0}, s_{1}\right]$} & {$\left[s_{5}, s_{5}\right]$} & {$\left[s_{5}, s_{5}\right]$} \\
\hline & $V_{7}^{1}$ & {$\left[s_{5}, s_{5}\right]$} & {$\left[s_{3}, s_{5}\right]$} & {$\left[s_{0}, s_{3}\right]$} & $V_{17}^{1}$ & {$\left[s_{-2}, s_{1}\right]$} & {$\left[s_{2}, s_{2}\right]$} & {$\left[s_{0}, s_{2}\right]$} \\
\hline & $V_{8}^{1}$ & {$\left[s_{5}, s_{5}\right]$} & {$\left[s_{3}, s_{5}\right]$} & {$\left[s_{0}, s_{3}\right]$} & $V_{18}^{1}$ & {$\left[s_{-2}, s_{1}\right]$} & {$\left[s_{2}, s_{2}\right]$} & {$\left[s_{2}, s_{2}\right]$} \\
\hline & $V_{9}^{1}$ & {$\left[s_{5}, s_{5}\right]$} & {$\left[s_{3}, s_{5}\right]$} & {$\left[s_{0}, s_{3}\right]$} & $V_{19}^{1}$ & {$\left[s_{0}, s_{1}\right]$} & {$\left[s_{5}, s_{5}\right]$} & {$\left[s_{5}, s_{5}\right]$} \\
\hline & $V_{10}^{1}$ & {$\left[s_{1}, s_{1}\right]$} & {$\left[s_{4}, s_{5}\right]$} & {$\left[s_{2}, s_{3}\right]$} & $V_{20}^{1}$ & {$\left[s_{3}, s_{4}\right]$} & {$\left[s_{3}, s_{4}\right]$} & {$\left[s_{3}, s_{4}\right]$} \\
\hline \multirow[t]{10}{*}{2} & $V_{1}^{2}$ & {$\left[s_{3}, s_{5}\right]$} & {$\left[s_{3}, s_{5}\right]$} & {$\left[s_{3}, s_{5}\right]$} & $V_{11}^{2}$ & {$\left[s_{4}, s_{5}\right]$} & {$\left[s_{4}, s_{5}\right]$} & {$\left[s_{4}, s_{5}\right]$} \\
\hline & $V_{2}^{2}$ & {$\left[s_{3}, s_{5}\right]$} & {$\left[s_{3}, s_{5}\right]$} & {$\left[s_{3}, s_{3}\right]$} & $V_{12}^{2}$ & {$\left[s_{4}, s_{5}\right]$} & {$\left[s_{4}, s_{5}\right]$} & {$\left[s_{4}, s_{5}\right]$} \\
\hline & $V_{3}^{2}$ & {$\left[s_{3}, s_{5}\right]$} & {$\left[s_{3}, s_{5}\right]$} & {$\left[s_{3}, s_{3}\right]$} & $V_{13}^{2}$ & {$\left[s_{4}, s_{5}\right]$} & {$\left[s_{4}, s_{5}\right]$} & {$\left[s_{4}, s_{5}\right]$} \\
\hline & $V_{4}^{2}$ & {$\left[s_{3}, s_{5}\right]$} & {$\left[s_{3}, s_{5}\right]$} & {$\left[s_{3}, s_{3}\right]$} & $V_{14}^{2}$ & {$\left[s_{4}, s_{5}\right]$} & {$\left[s_{4}, s_{5}\right]$} & {$\left[s_{4}, s_{4}\right]$} \\
\hline & $V_{5}^{2}$ & {$\left[s_{3}, s_{5}\right]$} & {$\left[s_{3}, s_{4}\right]$} & {$\left[s_{3}, s_{3}\right]$} & $V_{15}^{2}$ & {$\left[s_{4}, s_{5}\right]$} & {$\left[s_{4}, s_{5}\right]$} & {$\left[s_{4}, s_{5}\right]$} \\
\hline & $V_{6}^{2}$ & {$\left[s_{5}, s_{5}\right]$} & {$\left[s_{3}, s_{5}\right]$} & {$\left[s_{0}, s_{3}\right]$} & $V_{16}^{2}$ & {$\left[s_{3}, s_{4}\right]$} & {$\left[s_{3}, s_{4}\right]$} & {$\left[s_{3}, s_{4}\right]$} \\
\hline & $V_{7}^{2}$ & {$\left[s_{3}, s_{5}\right]$} & {$\left[s_{3}, s_{4}\right]$} & {$\left[s_{2}, s_{3}\right]$} & $V_{17}^{2}$ & {$\left[s_{3}, s_{4}\right]$} & {$\left[s_{3}, s_{4}\right]$} & {$\left[s_{3}, s_{4}\right]$} \\
\hline & $V_{8}^{2}$ & {$\left[s_{5}, s_{5}\right]$} & {$\left[s_{3}, s_{5}\right]$} & {$\left[s_{0}, s_{3}\right]$} & $V_{18}^{2}$ & {$\left[s_{5}, s_{5}\right]$} & {$\left[s_{3}, s_{5}\right]$} & {$\left[s_{0}, s_{3}\right]$} \\
\hline & $V_{9}^{2}$ & {$\left[s_{5}, s_{5}\right]$} & {$\left[s_{3}, s_{5}\right]$} & {$\left[s_{0}, s_{3}\right]$} & $V_{19}^{2}$ & {$\left[s_{0}, s_{1}\right]$} & {$\left[s_{3}, s_{5}\right]$} & {$\left[s_{3}, s_{3}\right]$} \\
\hline & $V_{10}^{2}$ & {$\left[s_{5}, s_{5}\right]$} & {$\left[s_{3}, s_{5}\right]$} & {$\left[s_{0}, s_{3}\right]$} & $V_{20}^{2}$ & {$\left[s_{0}, s_{1}\right]$} & {$\left[s_{3}, s_{3}\right]$} & {$\left[s_{3}, s_{4}\right]$} \\
\hline \multirow[t]{10}{*}{3} & $V_{1}^{3}$ & {$\left[s_{3}, s_{4}\right]$} & {$\left[s_{3}, s_{4}\right]$} & {$\left[s_{3}, s_{4}\right]$} & $V_{11}^{3}$ & {$\left[s_{4}, s_{5}\right]$} & {$\left[s_{4}, s_{5}\right]$} & {$\left[s_{4}, s_{5}\right]$} \\
\hline & $V_{2}^{3}$ & {$\left[s_{3}, s_{4}\right]$} & {$\left[s_{3}, s_{4}\right]$} & {$\left[s_{3}, s_{4}\right]$} & $V_{12}^{3}$ & {$\left[s_{5}, s_{5}\right]$} & {$\left[s_{3}, s_{5}\right]$} & {$\left[s_{0}, s_{3}\right]$} \\
\hline & $V_{3}^{3}$ & {$\left[s_{4}, s_{5}\right]$} & {$\left[s_{4}, s_{5}\right]$} & {$\left[s_{4}, s_{5}\right]$} & $V_{13}^{3}$ & {$\left[s_{3}, s_{5}\right]$} & {$\left[s_{3}, s_{5}\right]$} & {$\left[s_{3}, s_{4}\right]$} \\
\hline & $V_{4}^{3}$ & {$\left[s_{3}, s_{5}\right]$} & {$\left[s_{3}, s_{5}\right]$} & {$\left[s_{3}, s_{3}\right]$} & $V_{14}^{3}$ & {$\left[s_{3}, s_{4}\right]$} & {$\left[s_{3}, s_{4}\right]$} & {$\left[s_{3}, s_{4}\right]$} \\
\hline & $V_{5}^{3}$ & {$\left[s_{3}, s_{5}\right]$} & {$\left[s_{3}, s_{5}\right]$} & {$\left[s_{3}, s_{3}\right]$} & $V_{15}^{3}$ & {$\left[s_{5}, s_{5}\right]$} & {$\left[s_{3}, s_{5}\right]$} & {$\left[s_{2}, s_{3}\right]$} \\
\hline & $V_{6}^{3}$ & {$\left[s_{4}, s_{5}\right]$} & {$\left[s_{4}, s_{5}\right]$} & {$\left[s_{4}, s_{5}\right]$} & $V_{16}^{3}$ & {$\left[s_{3}, s_{4}\right]$} & {$\left[s_{3}, s_{4}\right]$} & {$\left[s_{3}, s_{4}\right]$} \\
\hline & $V_{7}^{3}$ & {$\left[s_{4}, s_{5}\right]$} & {$\left[s_{4}, s_{5}\right]$} & {$\left[s_{4}, s_{5}\right]$} & $V_{17}^{3}$ & {$\left[s_{3}, s_{4}\right]$} & {$\left[s_{3}, s_{3}\right]$} & {$\left[s_{3}, s_{4}\right]$} \\
\hline & $V_{8}^{3}$ & {$\left[s_{4}, s_{5}\right]$} & {$\left[s_{3}, s_{5}\right]$} & {$\left[s_{3}, s_{3}\right]$} & $V_{18}^{3}$ & {$\left[s_{4}, s_{5}\right]$} & {$\left[s_{4}, s_{5}\right]$} & {$\left[s_{4}, s_{5}\right]$} \\
\hline & $V_{9}^{3}$ & {$\left[s_{3}, s_{4}\right]$} & {$\left[s_{2}, s_{4}\right]$} & {$\left[s_{3}, s_{4}\right]$} & $V_{19}^{3}$ & {$\left[s_{3}, s_{4}\right]$} & {$\left[s_{1}, s_{1}\right]$} & {$\left[s_{0}, s_{1}\right]$} \\
\hline & $V_{10}^{3}$ & {$\left[s_{3}, s_{4}\right]$} & {$\left[s_{3}, s_{4}\right]$} & {$\left[s_{3}, s_{4}\right]$} & $V_{20}^{3}$ & {$\left[s_{3}, s_{3}\right]$} & {$\left[s_{1}, s_{1}\right]$} & {$\left[s_{0}, s_{1}\right]$} \\
\hline
\end{tabular}

Table 4 The public expectations for different attributes

\begin{tabular}{|c|c|c|c|c|c|}
\hline \multicolumn{2}{|l|}{ Attribute 1} & \multicolumn{2}{|l|}{ Attribute 2} & \multicolumn{2}{|l|}{ Attribute 3} \\
\hline Serial number & Expectation & Serial number & Expectation & Serial number & Expectation \\
\hline 1 & {$\left[s_{3}, s_{4}\right]$} & 1 & {$\left[s_{2}, s_{4}\right]$} & 1 & {$\left[s_{4}, s_{5}\right]$} \\
\hline 2 & {$\left[s_{3}, s_{4}\right]$} & 2 & {$\left[s_{1}, s_{2}\right]$} & 2 & {$\left[s_{4}, s_{5}\right]$} \\
\hline$\cdots$ & $\cdots$ & $\cdots$ & $\cdots$ & $\cdots$ & $\cdots$ \\
\hline 4712 & {$\left[s_{3}, s_{5}\right]$} & 4712 & {$\left[s_{2}, s_{3}\right]$} & 4712 & {$\left[s_{2}, s_{3}\right]$} \\
\hline 4713 & {$\left[s_{3}, s_{5}\right]$} & 4713 & {$\left[s_{2}, s_{2}\right]$} & 4713 & {$\left[s_{3}, s_{4}\right]$} \\
\hline
\end{tabular}

(2) Calculation of the expert group's preferences.

According to the clustering method described by Xu et al. [38], set the clustering threshold as $\lambda_{1}=0.89, \lambda_{2}=0.94$, and $\lambda_{3}=0.92$, respectively. And carry out the clustering operation to each set. The clustering results of each alternative are shown in Table 5. Then, use Eqs. (9-11) to obtain the expert group's preference for each alternative, as shown in Table 6.
(3) Measurement and optimization of the conflict of the expert group's preference.

Set $\theta=0.1$ as the conflict threshold of the expert group's preference, and calculate the expert group's preference conflict in each set. The results are $\operatorname{GCI}\left(Y_{1}\right)=0.1183$, $\operatorname{GCI}\left(Y_{2}\right)=0.0718$, and $\operatorname{GCI}\left(Y_{3}\right)=0.0608$, respectively. It can be seen that the expert group's preference conflict 
Table 5 Clustering results of each alternative

\begin{tabular}{|c|c|c|c|c|}
\hline Alternative & Aggregation & $\begin{array}{l}\text { Weight of the } \\
\text { aggregation }\end{array}$ & Experts of the aggregation & Experts' aggregation preference \\
\hline \multirow[t]{5}{*}{1} & $C_{1}^{1}$ & 0.45 & $\begin{array}{l}V_{1}^{1}, V_{2}^{1}, V_{5}^{1}, V_{6}^{1}, V_{7}^{1} \\
V_{8}^{1}, V_{9}^{1}, V_{11}^{1}, V_{12}^{1}\end{array}$ & {$\left[s_{4.78}, s_{5.00}\right]\left[s_{3.22}, s_{5.00}\right]\left[s_{0.22}, s_{3.00}\right]$} \\
\hline & $C_{2}^{1}$ & 0.20 & $V_{3}^{1}, V_{10}^{1}, V_{13}^{1}, V_{15}^{1}$ & {$\left[s_{1.00}, s_{1.00}\right]\left[s_{4.00}, s_{5.00}\right]\left[s_{2.00}, s_{3.00}\right]$} \\
\hline & $C_{3}^{1}$ & 0.15 & $V_{4}^{1}, V_{14}^{1}, V_{20}^{1}$ & {$\left[s_{3.00}, s_{4.00}\right]\left[s_{3.00}, s_{4.00}\right]\left[s_{3.00}, s_{4.00}\right]$} \\
\hline & $C_{4}^{1}$ & 0.10 & $V_{16}^{1}, V_{19}^{1}$ & {$\left[s_{0.00}, s_{1.00}\right]\left[s_{5.00}, s_{5.00}\right]\left[s_{5.00}, s_{5.00}\right]$} \\
\hline & $C_{5}^{1}$ & 0.10 & $V_{17}^{\mathrm{l}}, V_{18}^{\mathrm{l}}$ & {$\left[s_{-2.00}, s_{1.00}\right]\left[s_{2.00}, s_{2.00}\right]\left[s_{1.00}, s_{2.00}\right]$} \\
\hline \multirow[t]{4}{*}{2} & $C_{1}^{2}$ & 0.40 & $\begin{array}{l}V_{1}^{2}, V_{2}^{2}, V_{3}^{2}, V_{4}^{2} \\
V_{5}^{2}, V_{7}^{2}, V_{16}^{2}, V_{17}^{2}\end{array}$ & {$\left[s_{3.00}, s_{4.75}\right]\left[s_{3.00}, s_{4.50}\right]\left[s_{2.88}, s_{3.50}\right]$} \\
\hline & $C_{2}^{2}$ & 0.25 & $V_{6}^{2}, V_{8}^{2}, V_{9}^{2}, V_{10}^{2}, V_{18}^{2}$ & {$\left[s_{5.00}, s_{5.00}\right]\left[s_{3.00}, s_{5.00}\right]\left[s_{0.00}, s_{3.00}\right]$} \\
\hline & $C_{3}^{2}$ & 0.25 & $V_{11}^{2}, V_{12}^{2}, V_{13}^{2}, V_{14}^{2}, V_{15}^{2}$ & {$\left[s_{4.00}, s_{5.00}\right]\left[s_{4.00}, s_{5.00}\right]\left[s_{4.00}, s_{4.80}\right]$} \\
\hline & $C_{4}^{2}$ & 0.10 & $V_{19}^{2}, V_{20}^{2}$ & {$\left[s_{0.00}, s_{1.00}\right]\left[s_{3.00}, s_{4.00}\right]\left[s_{3.00}, s_{3.50}\right]$} \\
\hline \multirow[t]{4}{*}{3} & $C_{1}^{3}$ & 0.55 & $\begin{array}{l}V_{1}^{3}, V_{2}^{3}, V_{4}^{3}, V_{5}^{3}, V_{8}^{3}, V_{9}^{3}, \\
V_{10}^{3}, V_{13}^{3}, V_{14}^{3}, V_{16}^{3}, V_{17}^{3}\end{array}$ & {$\left[s_{3.09}, s_{4.36}\right]\left[s_{2.91}, s_{4.27}\right]\left[s_{3.00}, s_{3.73}\right]$} \\
\hline & $C_{2}^{3}$ & 0.25 & $V_{3}^{3}, V_{6}^{3}, V_{7}^{3}, V_{11}^{3}, V_{18}^{3}$ & {$\left[s_{4.00}, s_{5.00}\right]\left[s_{4.00}, s_{5.00}\right]\left[s_{4.00}, s_{5.00}\right]$} \\
\hline & $C_{3}^{3}$ & 0.10 & $V_{12}^{3}, V_{15}^{3}$ & {$\left[s_{5.00}, s_{5.00}\right]\left[s_{3.00}, s_{5.00}\right]\left[s_{1.00}, s_{3.00}\right]$} \\
\hline & $C_{4}^{3}$ & 0.10 & $V_{19}^{3}, V_{20}^{3}$ & {$\left[s_{3.00}, s_{3.50}\right]\left[s_{1.00}, s_{1.00}\right]\left[s_{0.00}, s_{1.00}\right]$} \\
\hline
\end{tabular}

Table 6 The expert group's preferences of each alternative

\begin{tabular}{ll}
\hline Alternative & Expert group's preference \\
\hline 1 & {$\left[s_{2.60}, s_{3.25}\right]\left[s_{3.40}, s_{4.55}\right]\left[s_{1.55}, s_{3.25}\right]$} \\
2 & {$\left[s_{3.45}, s_{4.50}\right]\left[s_{3.25}, s_{4.70}\right]\left[s_{2.45}, s_{3.70}\right]$} \\
3 & {$\left[s_{3.50}, s_{4.50}\right]\left[s_{3.00}, s_{4.20}\right]\left[s_{2.75}, s_{3.70}\right]$} \\
\hline
\end{tabular}

in set $\boldsymbol{\Omega}_{1}$ is too large and its aggregation weight needs to be optimized. Substitute the relevant information of set $\boldsymbol{\Omega}_{1}$ into model (M-2) and solve it. Set the step size of the maximum adjustment proportion of the aggregation weights as $\Delta_{0}=0.1$. It can be found that the model has an optimal solution when $C=4$, and the optimized aggregation weight is $\mathbf{w}_{1}^{*}=(0.54,0.12,0.21,0.06,0.07)^{\mathbf{T}}$. Substitute $\mathbf{w}_{1}^{*}$ into Eq. (11) and the optimized expert group's preference is obtained, i.e., $Y_{1}^{*}=\left(\left[s_{3.19}, s_{3.79}\right]\left[s_{3.29}, s_{4.58}\right]\left[s_{1.36}, s_{3.26}\right]\right)$.

(4) Calculation of the public group's satisfaction.

Use Eqs. $(14,15)$ to analyze the statistical distribution of the public group's expectation under different scales. The results are shown in Table 7.

Use Eqs. $(16,17)$ to determine the comprehensive satisfaction of each alternative, and the results are $b_{1}=0.7196, b_{2}=0.8243, b_{3}=0.8443$, respectively. Therefore, the ordering result of the three alternatives is $z_{1}<z_{2}<z_{3}$, and the optimal site for this project is alternative 3 .

\section{Comparison of the Methods}

The preference conflict resolution and scheme ranking are two important parts of group decision making. To highlight the effectiveness and applicability of the proposed approach, we compare our approach with existing approaches from the above two aspects.

\subsection{Comparison of the Preference Conflict Resolution Methods}

In this section, a comparison is provided to illustrate the superiority of the preference conflict resolution method we proposed. As two typical preference conflict resolution methods, Xu's approach [39] and Mao's approach [40] are introduced for comparation in this section. For convenience, we denote the conflict resolution methods proposed by $\mathrm{Xu}$ et al. [39] and Mao et al. [40] as $\mathbf{C R}_{\mathbf{1}}$ and $\mathbf{C R}_{\mathbf{2}}$, respectively.

Method $\mathbf{C R}_{\mathbf{1}}$ takes expert group's preference as a standard to adjust the preference information with oversize conflicts, to reduce conflict. We employ method $\mathbf{C R}_{1}$ to deal with the conflicts of expert group's preference in $\boldsymbol{\Omega}_{1}$, and the adjusted expert group's preference is $Y_{1}^{*}=\left(\left[s_{2.98}, s_{3.47}\right]\left[s_{3.43}, s_{4.69}\right]\left[s_{1.45}, s_{3.26}\right]\right)$ when $\operatorname{GCI}\left(Y_{1}\right)=0.0999<0.1$. The final sorting results obtained by method $\mathbf{C R}_{\mathbf{1}}$ are consistent with those obtained in this paper. 
Table 7 Distribution of the public group's expectation under different scales

\begin{tabular}{llllllll}
\hline Linguistic variables & & -5 & -4 & -3 & -2 & -1 & 0 \\
\hline $\begin{array}{l}\text { Proportion of public expectation } \\
\text { distribution }\end{array}$ & Attribute 1 & 0.0000 & 0.0000 & 0.0000 & 0.0000 & 0.0000 & 0.1239 \\
& Attribute 2 & 0.0000 & 0.0000 & 0.0000 & 0.0000 & 0.0000 & 0.0000 \\
& Attribute 3 & 0.0000 & 0.0000 & 0.0000 & 0.0000 & 0.0000 & 0.0329 \\
\hline Linguistic variables & & 1 & 2 & 3 & 4 & 5 & Total \\
\hline $\begin{array}{l}\text { Proportion of public expectation } \\
\text { distribution }\end{array}$ & Attribute 1 & 0.1715 & 0.3122 & 0.2231 & 0.1163 & 0.0530 & 1.0000 \\
& Attribute 2 & 0.0000 & 0.4799 & 0.4991 & 0.0108 & 0.0102 & 1.0000 \\
& Attribute 3 & 0.1120 & 0.3115 & 0.3148 & 0.2258 & 0.0030 & 1.0000 \\
\hline
\end{tabular}

However, we note that method $\mathbf{C R}_{\mathbf{1}}$ has obvious limitations in resolving group preference conflicts. Method $\mathbf{C R}_{\mathbf{1}}$ can adjust only one aggregation preference per round. Therefore, several interaction adjustments may be needed to achieve conflict resolution, resulting in low efficiency.

Method $\mathbf{C R}_{\mathbf{2}}$ gives weight to each expert according to the distance between the individual preference value and the mean value of group preference to solve the problem of expert group's preference conflict. According to the principle of method $\mathbf{C R}_{\mathbf{2}}$, it can be seen that for each individual expert, the smaller the distance between individual preference and the mean value of group preferences, the larger is the expert weight value. Similarly, we employ method $\mathbf{C R}_{\mathbf{2}}$ to deal with the conflicts of expert group's preference in $\boldsymbol{\Omega}_{1}$. As shown in Table 5, five aggregates are formed after clustering operation in $\boldsymbol{\Omega}_{1}$. Each of the expert's aggregation in $\boldsymbol{\Omega}_{1}$ is regarded as an entity to be weighted. Using the method $\mathbf{C R}_{\mathbf{2}}$, the weights of the five aggregations are obtained: $\mathbf{w}_{1}^{*}=(0.14,0.36,0.25,0.14,0.11)^{\mathbf{T}}$. The expert group's preference is $Y_{1}^{*}=\left(\left[s_{1.56}, s_{2.31}\right]\left[s_{3.56}, s_{4.42}\right]\left[s_{2.31}, s_{3.42}\right]\right)$. In this situation, the expert group's preference conflict in set $\boldsymbol{\Omega}_{1}$ is $G C I\left(Y_{1}\right)=0.1100>0.1$; compared with the method proposed in this paper, the conflict resolution effect of method $\mathbf{C R}_{\mathbf{2}}$ is not ideal. It can be found that the result of $Y_{1}^{*}$ obtained by method $\mathbf{C R}_{\mathbf{2}}$ is quite different from those obtained in this paper. The main reason is that method $\mathbf{C} \mathbf{R}_{\mathbf{2}}$ is proposed for the routine decision problems with a small number of experts. However, for large group decision-making problems, in addition to the expert group's preference conflict, the number of experts in the aggregation should also be considered when the aggregation is weighted. Generally speaking, the more experts in the aggregation, the more important are the aggregation's opinions, and the bigger should be the weight given. The method $\mathbf{C R}_{\mathbf{2}}$ only takes the disperse effect of expert opinions into consideration without the number of experts in each aggregation when giving weights to the aggregations. Therefore, method $\mathbf{C R}_{\mathbf{2}}$ is not suitable for large group decision making.
Compared with the above two methods, the conflict resolution method based on aggregation weight optimization in this paper has the following three advantages: (1) reasonable weight of aggregation preference can be obtained in a short time, and the expert group's preferences have good consistency, ensuring the efficiency of conflict resolution; (2) the initial aggregation weight is determined according to the number of experts in each aggregation, which highlights the preference importance of each aggregation; (3) the optimization model aims at minimizing the adjustment range of the aggregation weights and sets constraints to limit the modification range of the aggregation weights, to ensure the expression effectiveness of experts' group preferences.

\subsection{Comparison of Alternative Sorting Methods Based on Reference Points}

To show the advantages of our proposed approach using public expectations as the reference points, two common and representative alternative sorting methods based on reference points are selected for comparation: the prospect value method and TOPSIS method.

When using the prospect value method to make decisions, the reference points of each attribute need to be set in advance. Then, calculate the attribute prospect value of each alternative based on the distance between the attribute value of each alternative and its corresponding reference point. Finally, the comprehensive prospect value of each alternative can be obtained by combining the weight of each attribute [41]. However, in the decision making of major livelihood projects, the public group's expectation for each attribute is counted based on the statistics of linguistic scale, which is discrete and cannot be directly used as the reference points of prospect value method. On the basis of the statistical distribution of public group's expectation at different linguistic 
Table 8 Alternative sorting results obtained by different methods

\begin{tabular}{lll}
\hline Methods & Evaluation value & Sorting result \\
\hline The prospect value method & $b_{1}=0.0568, b_{2}=0.1457, b_{3}=0.1481$ & $z_{1}<z_{2}<z_{3}$ \\
The TOPSIS method & $b_{1}=0.8199, b_{2}=0.8651, b_{3}=0.8601$ & $z_{1}<z_{3}<z_{2}$ \\
The method in this paper & $b_{1}=0.7196, b_{2}=0.8243, b_{3}=0.8443$ & $z_{1}<z_{2}<z_{3}$ \\
\hline
\end{tabular}

scales (See in Sect. 4), we use $\widetilde{\varepsilon}_{j}$ to denote the reference points of attribute $j$ for prospect value method, $\widetilde{\varepsilon}_{j}=q_{j}\left(s_{-5}\right) s_{-5} \oplus q_{j}\left(s_{-4}\right) s_{-4} \oplus \ldots \oplus q_{j}\left(s_{4}\right) s_{4} \oplus q_{j}\left(s_{5}\right) s_{5}, j=1,2, \ldots, N$. Вy using the prospect value method, the comprehensive prospect value of each alternative is obtained and the alternatives are sorted, as shown in Table 8.

The TOPSIS method evaluates the alternatives by analyzing the distance between the actual evaluation value of each attribute and the positive and negative ideal points [42]. Based on the value range of expert group's preferences, the negative and positive ideal point of attribute $j$ are denoted as $\tilde{y}_{j}^{-}=\left[s_{-5}, s_{-5}\right]$ and $\tilde{y}_{j}^{+}=\left[s_{5}, s_{5}\right]$, respectively. By using the TOPSIS method, the alternative sorting results can be obtained and is shown in Table 8 .

As can be seen from Table 8, the results obtained in this paper are consistent with those obtained by the prospect value method, but inconsistent with those obtained by the TOPSIS method. The main reasons for the discrepant results of the three methods include the different setting of reference points and the different basis of the alternative evaluation.

(1) About the setting of reference point. As mentioned previously, the prospect value method is more suitable for decision-making problems with single or small number of reference points. However, due to the characteristics of public expectations, which include large volume and high dispersion, it is necessary to set multiple reference points to ensure the effectiveness of decision making. Therefore, the prospect value method is not suitable for this type of problems. The reference points setting of TOPSIS method only needs to consider the range of attribute evaluation value, without considering the other factors. Specifically, taking the numerical calculation in Sect. 4 as an example, when using the TOPSIS method to set the positive and negative ideal points, only the value range of expert group's preference is considered. As a result, the public group's expectation cannot be effectively reflected in the decision results. Comparatively, the method proposed in this paper is more suitable to take public group's expectation as reference points and can better meet the needs of solving such problems.

(2) About the basis of the alternative evaluation. Both the prospect value method and TOPSIS method evaluate the alternatives according to the distance between different attribute values and their corresponding reference points. However, when the above two methods are used to evaluate the alternatives in reality, some extreme situations often occur, leading to deviation of decision results. For example, if an alternative performs far better than other alternatives on one attribute, other attributes in this alternative may not have advantages, or even be at a disadvantage. When using the prospect value method and TOPSIS method, the final weighted comprehensive evaluation value of this alternative may still be the highest, because the evaluation value of the advantage attribute is high enough. Therefore, the optimal alternative determined in those two ways may not guarantee the satisfactory performance for all attributes. The method proposed in this paper to measure the public group's satisfaction is different from the other two comparison methods in calculation principle. According to the public group's satisfaction and the proportions of the public at different scales, this paper calculates the public group's satisfaction for each alternative. The advantage of our proposed method is that it only considers whether the attribute value of the alternative reaches the established satisfaction reference points, and does not consider the distance between the attribute value of the alternative and the reference point, so it can effectively avoid the influence of some extreme attribute values on the decision results.

\section{Conclusions}

Taking the decision making of major livelihood projects as the research object, we have developed a multi-agent large group decision-making method in this study, which is oriented to the public expectation. Compared with other commonly used decision-making methods, the method proposed in this paper has the following advantages: (1) According to the deviation degree of evaluation information given by experts and the public, the value range of attribute weights is determined. A maximum entropy model is established to solve the attribute weights, which guarantees the weighting effectiveness of attribute. (2) The expert preferences of different alternatives are clustered, and the expert preferences with similar values are grouped into the same aggregation, which can reduce the dispersion of the expert preferences. The initial aggregation weight is set according to the number of experts in each aggregation, which can better reflect the importance of each aggregation. (3) A weight optimization model of experts' aggregation is constructed 
to effectively optimize the conflict of the experts' group preference, so that the opinions of group preferences can reach a consensus. (4) The public group's satisfaction of each alternative is measured based on the distribution of the public expectation, which makes the decision result in line with public opinion.

However, the method proposed in this paper mainly aims at the decision-making problem of major livelihood projects in a single stage. In fact, many major livelihood projects need to be decided at multiple stages before the final result can be determined. Therefore, the proposed method should be further extended and applied in multi-stage decision-making activities of major livelihood projects. In addition, the decision-making environment of major livelihood projects is relatively complex, the influence of the external environment on decision making should be taken into consideration in the future study.

Author contributions ZGJ identified this problem and constructed them. CCG performed the model building and was a major contributor in writing the manuscript. PB helped CCG to finish the expression of the article and the comparison of the decision methods. WP was responsible for the example part. All authors read and approved the final manuscript.

Funding This research was funded by the National Natural Science Foundation of China (nos. 71902058, 72073041, 71901074), supported by Hunan Provincial Natural Science Foundation of China (nos. 2018JJ3617, 2021JJ41088), the Social Science Foundation of Hunan Province (no. 19YBQ113), and the Scientific Research Foundation of Hunan Education Department (nos. 20B155, 19A06, 18B189).

Availability of data and material The data used to support the findings of this study are included in the manuscript.

\section{Declarations}

Conflict of interest The authors declare no competing conflict.

Ethics approval and consent to participate Not applicable.

Open Access This article is licensed under a Creative Commons Attribution 4.0 International License, which permits use, sharing, adaptation, distribution and reproduction in any medium or format, as long as you give appropriate credit to the original author(s) and the source, provide a link to the Creative Commons licence, and indicate if changes were made. The images or other third party material in this article are included in the article's Creative Commons licence, unless indicated otherwise in a credit line to the material. If material is not included in the article's Creative Commons licence and your intended use is not permitted by statutory regulation or exceeds the permitted use, you will need to obtain permission directly from the copyright holder. To view a copy of this licence, visit http://creativecommons.org/licenses/by/4.0/.

\section{References}

1. Valenzuela, B.R., Yeo Chang, Y., Park, M.S., et al.: Local people's participation in mangrove restoration projects and impacts on social capital and livelihood: a case study in the Philippines. Forests 11(5), 1-24 (2020)

2. Shi, Q., Liu, Y., Zuo, J., et al.: On the management of social risks of hydraulic infrastructure projects in China: a case study. Int J Project Manag 33(3), 483-496 (2015)

3. Labella, Á., Liu, Y., Rodríguez, R.M., et al.: Analyzing the performance of classical consensus models in large scale group decision making: a comparative study. Appl Soft Comput 67, 677-690 (2018)

4. Rodríguez, R.M., Labella, Á., De Tré, G., et al.: A large scale consensus reaching process managing group hesitation. Knowl Based Syst 159, 86-97 (2018)

5. Wu, Z.B., Xu, J.P.: A consensus model for large-scale group decision making with hesitant fuzzy information and changeable clusters. Inf Fus 41, 217-231 (2018)

6. Cao, J., Xu, X.H., Dai, F., et al.: An evolution model of risk preference influenced by extremists in large group emergency consensus process. J Intell Fuzzy Syst 39(2), 1-14 (2020)

7. Cai, C.G., Xu, X.H., Wang, P., et al.: A multi-stage conflict style large group emergency decision-making method. Soft Comput 21(19), 5765-5778 (2017)

8. Zha, Q.B., Liang, H.M., Kou, G., et al.: A feedback mechanism with bounded confidence-based optimization approach for consensus reaching in multiple attribute large-scale group decisionmaking. IEEE Trans Comput Soc Syst 6(5), 994-1006 (2019)

9. Zhang, B.W., Liang, H.M., Gao, Y., et al.: The optimizationbased aggregation and consensus with minimum-cost in group decision making under incomplete linguistic distribution context. Knowl Based Syst 162, 92-102 (2018)

10. Zhang, B.W., Dong, Y.C., Xu, Y.F.: Multiple attribute consensus rules with minimum adjustments to support consensus reaching. Knowl Based Syst 67, 35-48 (2014)

11. Xu, J.P., Wu, Z.B., Zhang, Y.: Consensus based method for multi-criteria group decision making under uncertain linguistic setting. Group Decis Negot 23(1), 127-148 (2014)

12. Lu, Y.L., Xu, Y.J., Herrera-Viedma, E., et al.: Consensus of large-scale group decision making in social network: the minimum cost model based on robust optimization. Inf Sci 547, 910-930 (2021)

13. Chao, X.R., Kou, G., Peng, Y., et al.: Large-scale group decision-making with non-cooperative behaviors and heterogeneous preferences: an application in financial inclusion. Eur J Oper Res 288(1), 271-293 (2021)

14. Nyandoro, K.: Analysis of public participation on utilization of resources in Mandera west sub county, Mandera, Kenya. J Public Policy Gov 5(1), 1-24 (2021)

15. Palen, L., Anderson, K., Mark, G., et al.: A vision for technologymediated support for public participation \& assistance in mass emergencies \& disasters. ACM-BCS Vis Comput Sci 10, 1-12 (2010)

16. Yao, X., He, J., Bao, C.: Public participation modes in China's environmental impact assessment process: An analytical framework based on participation extent and conflict level. Environ Impact Assess Rev 84, 106400 (2020)

17. Zhang, X., Xu, J., Ju, Y.: Public participation in NIMBY risk mitigation: a discourse zoning approach in the Chinese context. Land Use Policy 77, 559-575 (2018) 
18. Dube, C., Mnguni, L., Tschudin, A.: Peacebuilding through public participation mechanisms in local government: the case study of Mbizana local municipality, South Africa. J Illicit Econ Dev 2(2), 1-14 (2021)

19. National Research Council: Public participation in environmental assessment and decision making. National Academies Press, Washington (2008)

20. Tàbara, D., Saurí, D., Cerdan, R.: Forest fire risk management and public participation in changing socioenvironmental conditions: a case study in a Mediterranean region. Risk Anal Int J 23(2), 249-260 (2003)

21. Wang, Y.L., Gao, R.L.: Risk distribution and benefit analysis of PPP projects based on public participation. Int J Strateg Prop Manag 24(4), 215-225 (2020)

22. Drazkiewicz, A., Challies, E., Newig, J.: Public participation and local environmental planning: testing factors influencing decision quality and implementation in four case studies from Germany. Land Use Policy 46, 211-222 (2015)

23. Wu, S.N., Lei, Y., Cui, P., et al.: Chinese public participation monitoring and warning system for geological hazards. J Mt Sci 17(7), 1553-1564 (2020)

24. Lamouroux, N., Gore, J.A., Lepori, F., et al.: The ecological restoration of large rivers needs science-based, predictive tools meeting public expectations: an overview of the R hône project. Freshw Biol 60(6), 1069-1084 (2015)

25. Yildiz, A., Ayyildiz, E., Gumus, A.T., et al.: A framework to prioritize the public expectations from water treatment plants based on trapezoidal type-2 fuzzy Ahp method. Environ Manag 9, 1-10 (2020)

26. Hietbrink, M., Hartmann, A., Dewulf, G.P.M.: Stakeholder expectation and satisfaction in road maintenance. Procedia Soc Behav Sci 48, 266-275 (2012)

27. Zhu, J.J., Ma, Z.Z., Wang, H.H., et al.: Risk decision-making method using interval numbers and its application based on the prospect value with multiple reference points. Inf Sci 12(3), 385386 (2017)

28. Li, X.H., Chen, X.H.: Value determination method based on multiple reference points under a trapezoidal intuitionistic fuzzy environment. Appl Soft Comput J 63, 39-49 (2018)

29. Gao, J., Xu, Z.S., Liao, H.C.: A dynamic reference point method for emergency response under hesitant probabilistic fuzzy environment. Int J Fuzzy Syst 19(5), 1261-1278 (2017)

30. Wang, L., Zhang, Z.X., Wang, Y.M.: A prospect theory-based interval dynamic reference point method for emergency decision making. Expert Syst Appl 42(23), 9379-9388 (2015)
31. Song, M.X., Jiang, W., Xie, C.H., et al.: A new interval numbers power average operator in multiple attribute decision making. Int J Intell Syst 32(6), 631-644 (2017)

32. Dong, J.Y., Wan, S.P., Chen, S.M.: Fuzzy best-worst method based on triangular fuzzy numbers for multi-criteria decision-making. Inf Sci 547, 1080-1104 (2021)

33. Dutta, P., Saikia, B.: Arithmetic operations on normal semi elliptic intuitionistic fuzzy numbers and their application in decisionmaking. Granul Comput 6(1), 163-179 (2021)

34. Liu, P.D., Zhang, X.: The study on multi-attribute decision-making with risk based on linguistic variable. Int J Comput Intell Syst 3(5), 601-609 (2010)

35. Liu, P.D., Teng, F.: An extended TODIM method for multiple attribute group decision-making based on 2-dimension uncertain linguistic variable. Complexity 21(5), 20-30 (2016)

36. Liu, P.D., Qin, X.Y.: Maclaurin symmetric mean operators of linguistic intuitionistic fuzzy numbers and their application to multiple-attribute decision-making. J Exp Theor Artif Intell 29(6), 1173-1202 (2017)

37. Xu, Z.S.: Induced uncertain linguistic OWA operators applied to group decision making. Inf Fus 7(2), 231-238 (2006)

38. Xu, X.H., Cai, C.G., Chen, X.H., et al.: A multi-attribute large group emergency decision making method based on group preference consistency of generalized interval-valued trapezoidal fuzzy numbers. J Syst Sci Syst Eng 24(2), 211-228 (2015)

39. Xu, J.P., Wu, Z.B.: A discrete consensus support model for multiple attribute group decision making. Knowl Based Syst 24, 1196-1202 (2011)

40. Mao, J.J., Wang, C.C., Yao, D.B.: Method for multi-attribute group decision-making based on multi-experts' interval numbers. J Comput Appl 32(3), 649-653 (2012)

41. Wang, L., Wang, Y.M., Martinez, L.: A group decision method based on prospect theory for emergency situations. Inf Sci 418, 119-135 (2017)

42. Wei, Y., Liu, P.: Risk evaluation method of high-technology based on uncertain linguistic variable and TOPSIS method. J Comput 4(3), 276-282 (2009)

Publisher's Note Springer Nature remains neutral with regard to jurisdictional claims in published maps and institutional affiliations. 